\title{
Medical Device
}

National Cancer Institute

\section{Source}

National Cancer Institute. Medical Device. NCI Thesaurus. Code C16830.

Any physical object that is useful for prevention, diagnosis, monitoring, or treatment of disease or other conditions. 